\title{
Dorothy Tanck de Estrada (2013), Independencia y educación. Cultura cívica, educación indigena y literatura infantil, México, El Colegio de México
}

\author{
Eugenia Roldán Vera \\ Departamento de Investigaciones \\ Educativas, Cinvestav \\ eroldan@cinvestav.mx
}

Esta compilación de trabajos de Dorothy Tanck forma parte de la serie "Antologías" de El Colegio de México, A. C., que, con motivo del aniversario número 70 de dicha institución, recoge textos fundamentales de sus investigadores relativos a la independencia o a la revolución mexicanas. El volumen reúne 13 trabajos de Tanck sobre distintos aspectos de la historia de la educación en el siglo XVIII y hasta 1840, publicados entre 1977 y 2011.

Los textos compilados tienen distintos grados de especialización. Algunos son de clara divulgación, como "El Siglo de las Luces", que originalmente apareció en Historia mínima. La educación en México (México, El Colegio de México, 2010). Otros son conferencias publicadas por primera vez, como "Siete innovaciones y una falacia sobre la educación elemental durante la época de la independencia" (conferencia magistral presentada en el XII Encuentro Internacional de Historia de la Educación, Morelia, México, 10-11 de noviembre, 2010). Y otros están escritos en un estilo mucho más especializado, como "Los pueblos y las escuelas en los albores de la independencia", extraído de la obra clásica de Tanck Pueblos de indios y educación en la época colonial (1999), o el trabajo "Estadísticas educativas y poblacionales, 1750-1840", que consta casi exclusivamente de tablas estadísticas sobre población, educación indígena y urbana de gran valor para el historiador de ese periodo. Tal variedad de estilos no demerita el valor de la compilación; antes bien, da una idea de la llegada de los trabajos de Tanck a públicos diversos: historiadores, maestros o cualquier interesado en la historia de la educación. Además, una lectura de conjunto de estos trabajos sirve para valorar el carácter pionero de las investigaciones de Tanck y constituye una invitación a profundizar en temáticas que ella trajo a la luz por primera vez y que aún están poco trabajadas. 
En conjunto, los textos reunidos versan sobre los tres rubros marcados en el título del libro: cultura cívica, educación indígena y literatura infantil. A continuación señalaré lo que, a mi entender, son las mayores aportaciones de Tanck en cada uno de esos tres rubros y que aparecen con claridad en los textos de este volumen. Posteriormente revisaré algunos aspectos de la perspectiva historiográfica desarrollada por Tanck a lo largo de más de cuatro décadas en la materia.

\section{Cultura cívica}

Dorothy Tanck fue pionera en advertir la simultaneidad de la enseñanza cívica en torno a las revoluciones atlánticas de finales del siglo XVIII, así como del carácter supranacional de los medios para impartirla. En su ensayo "Los catecismos políticos: de la revolución francesa al México independiente", incluido en este volumen, Tanck pone el foco en un género específico de manuales escolares - los manuales en forma de preguntas y respuestas, semejantes al catecismo católico - y muestra cómo un mismo género de libro para la enseñanza pudo servir para objetivos políticos muy diversos: promover los valores de la Revolución francesa, defender los principios monárquicos españoles, divulgar los fundamentos de la Constitución monárquica de 1812, o bien, para fomentar la lucha independentista. También Tanck fue de las primeras en advertir las implicaciones morales y cívicas que se le atribuían al sistema lancasteriano para la formación de ciudadanos en el México independiente, como lo muestra en el texto "Las escuelas lancasterianas en la ciudad de México, 1822-1842". Con todo, las áreas en las que Tanck ha profundizado más y en las que ha desarrollado sus principales aportaciones no son las de historia de la cultura cívica, sino sobre todo las de educación indígena y de literatura infantil.

\section{Educación indigena}

En varios de los trabajos aquí reunidos ("El siglo de las luces", "Pueblo de indios", "Los pueblos y las escuelas en los albores de la independencia") se reafirman de manera clara las tesis de la principal contribución de Dorothy Tanck — formulada con gran profundidad en su libro Pueblos de indios y educación - a nuestra comprensión de la historia de la educación indígena: la tradición escolar de los pueblos indígenas, en manos indígenas, heredada del periodo colonial. A mediados del siglo XVIII, tras ordenar la transferencia de las parroquias indígenas de manos de los frailes al clero secular, Carlos III mandó en 1773 que se establecieran escuelas de enseñanza de primeras letras en castellano en los pueblos de indios (y ya no sólo de doctrina cristiana), financiadas no por la Iglesia sino por los fondos de las cajas de comunidad de los indígenas. Esto daba al consejo gubernativo electo de los pueblos de 
indios - la "República" - cierto control sobre la selección del maestro (que en muchas ocasiones era un sacerdote) y sobre algunos aspectos de la enseñanza. Más aún, en el marco de las reformas borbónicas las cajas de comunidad de los pueblos de indios fueron sometidas a las mismas fiscalizaciones que los Ayuntamientos españoles; esto limitó lo que los pueblos podían gastar en fiestas religiosas pero aumentó lo que podían destinar al pago del maestro de escuela. A consecuencia de estas reformas, durante el periodo de 1773 a 1808 se establecieron escuelas de primeras letras en $26 \%$ del total de 4,468 pueblos de indios existentes en la Nueva España (con diferencias significativas entre las intendencias: en la de México, $43 \%$ de los pueblos tenían escuela). Aunque tras la Independencia, el número total de escuelas en las poblaciones indígenas parece haber descendido, otras investigaciones sugieren que estos desarrollos de la última parte del virreinato dejaron honda huella en las tradiciones locales de gestionar la escuela.

\section{Literatura infantil}

Tanck también ha sido pionera en la investigación de la enseñanza de la lectura y la escritura en el tránsito del siglo XVIII al XIX. En este volumen se reimprime su ensayo más completo al respecto: "La enseñanza de la lectura y de la escritura en la Nueva España, 1700-1821". Se trata de un estudio erudito sobre los manuales empleados en las escuelas de primeras letras de ese periodo, en el que ella revisa además la discusión pedagógica que se dio a finales del siglo XVIII en los reinos españoles entre la enseñanza por el silabeo frente a la enseñanza tradicional por el deletreo. En su análisis, toma en cuenta aspectos materiales de la enseñanza de la lectura y la escritura que son indispensables para comprender lo propiamente "educativo". Por ejemplo, considera cómo la cuestión de los derechos de impresión de las cartillas, catones y silabarios, incidió en la conservación de un método de enseñanza de lectura por sobre otro; así mismo, describe los utensilios que se empleaban para enseñar a escribir en las escuelas y analiza su relación con la práctica de enseñar la escritura de manera separada de la lectura.

Por otra parte, en los ensayos "El primer libro de texto gratuito en México: la biografía de una mujer indígena publicada en 1784" y "El primer libro recreativo para niños en México, 1802", Tanck nos acerca algunos textos de apoyo a la lectura que se usaron ampliamente en escuelas indígenas o urbanas. Esto abre vetas de investigación muy ricas sobre el acceso de la población novohispana de finales del siglo XVIII a la cultura impresa que hasta ahora, a mi entender, no han sido consideradas por nadie más. 


\section{La historiografía de la educación de Dorothy Tanck}

La perspectiva historiográfica que ha desarrollado la autora a lo largo de cuatro décadas, adecuadamente representada en esta compilación, aborda lo educativo desde las prácticas y sin pretensiones de legitimar el desarrollo del sistema educativo mexicano que se consolidó entre finales del siglo XIX y la tercera década del siglo Xx. Aunque considera las políticas educativas, la periodización de Tanck no está marcada por lo político, pues desde su clásico La educación ilustrada, 1786-1836: educación primaria en la ciudad de México (1977), Tanck examina tanto las rupturas como las continuidades entre la última etapa colonial y el primer liberalismo mexicano de la Independencia; esto reaparece en el presente volumen en el texto "Ilustración y liberalismo en el programa de educación primaria de Valentín Gómez Farías". Además, consigue descentrar al Estado como el principal proveedor de la educación, lo que le permite arrojar luz sobre incontables aspectos de gestión local y de cultura material de la escuela. Sus investigaciones muestran un panorama muy rico y variado sobre la educación mexicana anterior a los procesos de centralización estatal.

Con todo, las interpretaciones de Tanck no están exentas de una pequeña dosis de teleología pedagógica. Algunos de los trabajos contenidos en este volumen - sobre todo los más tempranos - manejan la hipótesis implícita de que en la historia de la educación, el avance de las prácticas pedagógicas sería progresivo y tendría que ir de lo menos pedagógico (por ejemplo, el deletreo o los libros más "aburridos") a lo más pedagógico (por ejemplo, el silabeo o los libros con contenido "recreativo")

Por otra parte, Tanck tiene una agenda política que yace bajo algunos aspectos de su interpretación de la educación elemental y superior en el siglo XVIII: procura destacar las aportaciones locales a lo pedagógico que ella considera "europeo". Así, insiste en que hubo autores novohispanos que "[... no sólo adaptaron ideas europeas a la realidad mexicana, sino que inventaron métodos nuevos y escribieron textos basados en su propia experiencia", y busca destacar la "contribución mexicana a la pedagogía de la época" (p. 47). Al hacerlo, Tanck adopta argumentos propios de los nacionalistas criollos del siglo XVIII — que ella analiza en su texto "El Siglo de las Luces" - en su reacción a las restricciones que la Corona les imponía para ocupar cátedras universitarias. No es casualidad que reproduzca el famoso reclamo de Antonio Alzate al peninsular Vicente Cervantes, titular de la cátedra de Botánica, sobre su apreciación del estado que guardaba la educación en la Nueva España:

Usted concibió [que] llegaba a un país monstruoso, lleno de bárbaros, y que venía a manifestar las riquezas que la naturaleza presenta y que en otros países son exquisitas, y ha encontrado más instrucción que la que concebía, y esto le tiene bien mortificado; pues sepa Usted que la química y demás ciencias naturales no son exóticas en el país, se cultivan con más aplicación que la que Usted juzga [p. 124]. 
En su intento por demostrar que en la Nueva España había más educación de la que la Corona borbona y los políticos de la Independencia quisieron admitir, Tanck incurre tendenciosamente en un cierto nacionalismo cultural que obscurece algunas posibilidades de interpretación distintas. Una reflexión sobre la naturaleza supranacional de lo educativo o un estudio de las pugnas de distintos grupos de poder dentro de la estructura del imperio español, que trasladaba lo político a la arena de la enseñanza, por ejemplo, enriquecería este tipo de explicaciones

Por otra parte, a lo largo de su trayectoria, Tanck ha desarrollado nuevos enfoques y algunas de sus primeras publicaciones se han revalorado a la luz de nuevas perspectivas historiográficas. Así, en este volumen, la inclusión del ensayo "La vida escolar antes y después de la Independencia”, uno de los capítulos secundarios de La educación ilustrada 1786-1836 (1977), constituye un acierto a la luz de las corrientes historiográficas que rescatan la vida cotidiana y la experiencia escolar. Y el ensayo "Pueblo de indios (definición)", preparado para el Diccionario de la independencia de México que editó la UNAM con motivo del bicentenario de la Independencia (2010), constituye una aportación original ubicada en la línea de la historia de los conceptos que busca un acercamiento a la historia social desde la historia de los usos del lenguaje. Este trabajo le permite a Tanck examinar históricamente la terminología empleada para designar a las poblaciones indígenas, examen que debería ser conocido por historiadores y hacedores de políticas públicas en general. "Pueblo de indios" era, durante la época colonial, un "[...] asentamiento de indios con gobernantes indígenas reconocido por el gobierno" (p. 145); estaba compuesto por dos instituciones: la "República" —el consejo gubernativo, electo cada año por una fracción o por la totalidad de los tributarios - y la "comunidad" - término referido al orden económico de los pueblos, que designaba la tesorería de los pueblos y hacía referencia a las tierras comunales, y los fondos y bienes que pertenecían al pueblo-. Las transformaciones en la forma de denominar a los indígenas en los dos siglos subsiguientes, como bien señala Tanck, obedecieron a desarrollos políticos, económicos y sociales diversos.

Cierro esta reseña con la mención de un aspecto editorial que por desgracia demerita la lectura del libro y que, aunque parezca menor, tiene implicaciones historiográficas importantes: la ausencia de referencias a las citas textuales en varios de los capítulos, publicados así originalmente en otras obras de divulgación tanto de El Colegio de México como de la UNAM. En esos casos, la falta de referencias bibliográficas, hemerográficas o de archivo impide al lector la consulta y cotejo con las fuentes originales. Aunque esto pareciera liberarlo de las incómodas notas al pie, el gesto también tiende a incrementar la distancia entre la erudición de quien escribe y la ignorancia de quien lee. Esto crea una dependencia del lector hacia el autor que limita el potencial "educativo" de este libro, en estos tiempos tan imprescindible. 